Article

\title{
Toward Improved Daily Cloud-Free Fractional Snow Cover Mapping with Multi-Source Remote Sensing Data in China
}

\author{
Jie Deng, Xiaodong Huang *, Qisheng Feng, Xiaofang Ma and Tiangang Liang \\ Key Laboratory of Grassland Agro-Ecology System, Ministry of Agriculture, College of Pastoral \\ Agriculture Science and Technology, Lanzhou University, Lanzhou 730020, China; \\ E-Mails: dengj2014@1zu.edu.cn (J.D.); fengqsh@1zu.edu.cn (Q.F.); ymaxiaofangy@163.com (X.M.); \\ tgliang@1zu.edu.cn (T.L.)
}

* Author to whom correspondence should be addressed; E-Mail: huangxd@1zu.edu.cn; Tel.: +86-931-8912-896; Fax: +86-931-8910-979.

Academic Editors: Xin Li, Yuei-An Liou, Qinhuo Liu, Alexander Kokhanovsky and Prasad S. Thenkabail

Received: 13 February 2015 / Accepted: 22 May 2015 / Published: 29 May 2015

\begin{abstract}
With the high resolution of optical data and the lack of weather effects of passive microwave data, we developed an algorithm to map daily cloud-free fractional snow cover (FSC) based on the Moderate Resolution Imaging Spectroradiometer (MODIS) standard daily FSC product, the Advanced Microwave Scanning Radiometer (AMSR2) snow water equivalent (SWE) product and digital elevation data. We then used the algorithm to produce a daily cloud-free FSC product with a resolution of $500 \mathrm{~m}$ for regions in China. In addition, we produced a high-resolution FSC map using a Landsat 8 Operational Land Imager (OLI) image as a true value to test the accuracy of the cloud-free FSC product developed in this study. The analysis results show that the daily cloud-free FSC product developed in this study can completely remove clouds and effectively improve the accuracy of snow area monitoring. Compared to the true value, the mean absolute error of our product is 0.20 , and its root mean square error is 0.29 . Thus, the synthesized product in this study can improve the accuracy of snow area monitoring, and the obtained snow area data can be used as reliable input parameters for hydrological and climate models. The land cover type and terrain factors are the main factors that limit the accuracy of the daily cloud-free FSC product developed in this study. These limitations can be further improved by improving the accuracy of the MODIS standard snow product for complicated underlying surfaces.
\end{abstract}


Keywords: MODIS; fractional snow cover product; cloud-removal algorithm; China

\section{Introduction}

Snow cover is an important component of land cover and plays a key role in balancing global energy and water resources because of its high albedo and thermal storage properties [1-3]. The spatial distribution of snow cover is a significant input factor in hydrological and climate models for mountain areas and seasonally snow-covered areas [4,5]. Because China covers a large territory, snow-covered areas are widespread in geographic space. Three main seasonally snow-covered areas are northern Xinjiang, northeastern Inner Mongolia, and the Tibetan Plateau [6-8]. Thus, precisely obtaining snow-covered area information via remote sensing is vitally important in understanding climate variations, performing water circulation and water resource investigations, and predicting and preventing snow-related disasters in China.

Because remote sensing is characterized by a number of advantages, including large-scale, fast, periodic, multi-scale, multi-spectrum, multi-temporal, and low-cost investigations, remote sensing is widely used in snow cover monitoring [9]. Since the launch of television infrared observation satellites (TIROS)-1 in 1960, with the capability to monitor snow cover, dozens of satellites have been used to monitor snow cover and have played an important role in it. Such snow cover products include Landsat and SPOT [10], AVHRR [11], VEGETATION [12], MODIS [13], SMMR, SSM/I [14,15] and AMSR-E [16]. The Moderate Resolution Imaging Spectroradiometer (MODIS) aboard the Terra and Aqua satellites features moderate spatial resolution, high spectral resolution, and high temporal resolution characteristics. The Terra satellite passes the equator at 10:30 am, while the Aqua satellite passes the equator at 1:30 pm. The MODIS aboard can acquire two observations in the daytime. Thus, MODIS is widely used in snow area monitoring [17-19]. However, optical sensors are easily affected by clouds because clouds prevent land information from being received by the optical sensors [20]. In addition, clouds and snow have quite similar optical characteristics in the visible and far infrared wave bands, making it difficult to distinguish one from another using this spectral range [9,21]. Although, many studies have shown that the daily MODIS snow products are characterized by high snow classification accuracy under clear sky condition in the Northern hemisphere [22-27]. The cloud contamination limited its capability for monitoring the snow-covered area. Therefore, removing the clouds and recovering the ground information for the cloud-contaminated images is often necessary in snow monitoring and other applications. Cloud pixels can be removed by similar pixel replacement guided with a spatio-temporal Markov random fields model [28], multi temporal dictionary learning [29], and also can refer to the multi-temporal regression analysis method used for recovering the missing pixels for Landsat ETM+ SLC-off imagery [30]. Studies on the cloud-removal algorithms of the current MODIS snow products mainly focus on binary snow products [31-38], and the methods include multi-day composited algorithms [34,35], algorithms based on snow water equivalent products obtained by microwave sensors [36,37], and the Snow line (SNOWL) algorithm, in which cloud pixels are re-classified based on characteristics of the snow cover spatial distribution [38]. However, multi-day composited algorithms can eliminate most cloud contaminations, but sacrifice the temporal resolution. 
Furthermore, a direct composite of MODIS and passive microwave snow products can completely eliminate the cloud, but reduce the accuracy of snow classification because of the low spatial resolution of the passive microwave snow products. SNOWL cloudless algorithm uses the reclassification approach whereby cloud pixels can be divided into snow, no-snow (land), and partial snow. However, the partial snow has some uncertainties, so it is hard to analyze the snow-covered area effectively [39,40].

During the binary snow mapping, this algorithm assumes that all pixels are pure and that a pixel corresponds to one object type. The land types are divided into snow areas and snow free areas; this extremely simplified treatment is one of the primary causes of the low accuracy associated with the monitoring of snow-covered areas. Because a number of climate and hydrological models require increasingly precise snow-covered area input parameters [41], the traditional binary snow cover mapping cannot satisfy the current demand. Sub-pixel snow mapping can overcome the low-accuracy limitations in monitoring regional snow-covered areas, and represent the gradual changes in snow cover in each pixel more accurately than the binary snow cover map [42]. A few researchers have recently studied the algorithm of the MODIS fractional snow cover (FSC) product using the linear spectrum decomposition method and have proposed a new sub-pixel snow classification algorithm based on mixed pixel decomposition $[42,43]$. Although these algorithms can improve the accuracy of snow cover mapping to a certain degree, the process involves the identification of image purity and the calculation of component ratios in each pixel using the least square method in the algorithms, which results in a large number of calculations and therefore cannot be applied to the mapping of in situ snow cover area ratios. In the versions of the MODIS snow cover products released by the NASA National Snow and Ice Data Center (NSIDC) that are newer than V005, FSC maps are included in the MODIS daily snow cover maps, in addition to the snow-covered binary maps. The FSC product was built based on the statistical model developed by Salomonson (2004) [44]. However, similar to the algorithm of the MODIS binary snow cover product, the model algorithm was developed in snow-covered areas in Alaska, Canada and Russia and therefore represents different types of snow cover, including glaciers, flat snow cover and taiga forest snow cover. Snow covers large areas to great depths in these countries. In contrast, in China, snow depth is quite shallow and spatially dispersed, which is quite different from the snow cover in the model's regions. Thus, the model requires further tests to verify whether this model can be applied to snow cover studies in China. Furthermore, this product is strongly affected by clouds and therefore cannot effectively predict regional and global snow-covered areas. Tang et al. [45] proposed a cloud-removal method based on the cubic spline function interpolation method for the Tibetan Plateau area. This method, however, needs to fit a function curve and cannot be applied to complicated and variable weather conditions. Thus, this method can only be applied to snow cover monitoring at certain regional scales.

Based on the MODIS binary snow-removal algorithm, Terra \MODIS and Aqua \MODIS daily FSC products, the AMSR2 snow water equivalent product (based on passive microwave data), terrain data, and the combined advantages of different cloud-removal algorithms, we aim to develop an automatic daily cloud-free FSC mapping algorithm, produce a daily cloud-free FSC product for regions in China, and test the accuracy of the developed product by comparing it to the FSC map produced by Landsat 8 data. 


\section{Data}

\subsection{MODIS FSC Product}

MODIS daily snow products MOD10A1 and MYD10A1 of V005 include 20 tiles used for regions of China during November 2013 to February 2014. The data are from the NSIDC and have a spatial resolution of $500 \mathrm{~m}$. The original data were in HDF format, the projection is sin-map projection, and the version used in this study is V005. These MODIS products include snow-covered area (SCA), snow albedo (SA), FSC and quality assessment (QA). The coding values of FSC are as follows: 0-100 are fractional snow cover; 22 night; 225 land; 237 mainland water body; 239 sea; and 250 cloud, and 200, 201, 254, and 255 represent missing data or meaningless data [9]. The format and coordinates of the original HDF-EOS MODIS data were converted and the images were merged using the MODIS Reprojection Tool (MRT) software [46]. The image files were converted to the GeoTIFF format, the projection was converted to the ellipsoid WGS84 geographic coordinates, and the nearest neighbor method was adopted for re-sampling. The MODIS FSC data for regions in China were obtained by cropping images in ArcGIS 10.1.

\subsection{AMSR2 Snow Water Equivalent (SWE) Product}

The Advanced Microwave Scanning Radiometer 2 (AMSR2) aboard the GCOM-W1 satellite, launched by the Japan Aerospace Exploration Agency (JAXA) on 18 May 2012, is greatly improved relative to the AMSR-E version. Its spatial resolution was increased $(10 \mathrm{~km})$ and a new frequency $(7.3 \mathrm{GHz})$ was added, resulting in seven frequencies from 6.9-89 GHz. Two dataset from ascending (13:00 PM) and descending (1:30 AM) orbit were included each day. Three levels exist in the AMSR2 product, and snow water equivalent is the second layer of the second level of the snow-depth product. The snow water equivalent (SWE) numerical coding values are as follows: positive values are snow water equivalents and -32761 to -32768 are data errors. The AMSR2 SWE data that temporally coincide with the MODIS FSC data are used in this study. The AMSR2 SWE data feature the GeoTIFF format, a $10 \mathrm{~km}$ spatial resolution and ellipsoid WGS84 geographic coordinates. The data were obtained from the GCOM-W1 data service website. The AMSR2 SWE data of descending orbit for the regions in China were selected by cropping the AMSR2 SWE images in ArcGIS 10.1 software.

\subsection{Landsat 8 OLI Data}

The Operational Land Imager (OLI) aboard the Landsat 8 satellite, launched successfully by NASA on 11 February 2013, has nine wave bands. The spatial resolution of eight of the wave bands is $30 \mathrm{~m}$, and the panchromatic band is $15 \mathrm{~m}$ (Table 1). The data were downloaded from the US Geological Survey (USGS) and Geospatial Data Cloud for free. We chose seven Landsat 8 OLI images in different regions on the same day to represent different snow cover type regions in China. For instance, the forest regions (L1, L2 and L3), cropland region (L4, L5 and L6), and alpine grassland regions (L7, L8 and L9) are "true values" to test the accuracy of the cloud-free FSC product developed in this study. The parameters of the data are listed in Table 2. 
Table 1. Spectral bands of the Landsat 8 OLI.

\begin{tabular}{ccccc}
\hline Band No. & Band & Bandwidth $(\boldsymbol{\mu m})$ & Spatial Resolution $(\mathbf{m})$ & Radiometric Resolution (bit) \\
\hline 1 & Coastal aerosol & $0.433-0.453$ & 30 & 12 \\
2 & Blue & $0.450-0.515$ & 30 & 12 \\
3 & Green & $0.525-0.600$ & 30 & 12 \\
4 & Red & $0.630-0.680$ & 30 & 12 \\
5 & Near Infrared & $0.845-0.885$ & 30 & 12 \\
6 & SWIR 1 & $1.560-1.660$ & 30 & 12 \\
7 & SWIR 2 & $2.100-2.300$ & 30 & 12 \\
8 & Panchromatic & $0.500-0.680$ & 15 & 12 \\
9 & Cirrus & $1.360-1.390$ & 30 & 12 \\
\hline
\end{tabular}

Table 2. Information on the Landsat 8 OLI data from January 16, 2014.

\begin{tabular}{cccccc}
\hline Number & Date & Main Land Cover Types & Strip Number & Line Number & Cloud (\%) \\
\hline L1 & 16 January 2014 & Shrublands and Forest & 122 & 23 & 3.18 \\
L2 & 16 January 2014 & Shrublands and Forest & 122 & 24 & 6.10 \\
L3 & 16 January 2014 & Shrublands and Forest & 122 & 26 & 8.55 \\
L4 & 26 December 2014 & Cropland & 119 & 27 & 3.07 \\
L5 & 5 February 2014 & Cropland & 118 & 28 & 9.10 \\
L6 & 16 January 2014 & Cropland & 122 & 40 & 4.81 \\
L7 & 16 January 2014 & Grasslands & 138 & 33 & 4.48 \\
L8 & 16 January 2014 & Grasslands & 138 & 34 & 6.62 \\
L9 & 16 January 2014 & Grasslands & 138 & 36 & 5.04 \\
\hline
\end{tabular}

\subsection{IGBP Land Cover Type Product}

The Internal Geosphere-Biosphere Program (IGBP) land cover type data are one of the classification products that use different strategies to extract land cover characteristics from MODIS/MCD12Q1 (V005) with a resolution of $500 \mathrm{~m}$ [47]. The IGBP divides land cover into 17 types, including 11 natural vegetation types, three land use and land mosaic types and three vegetation-free land types [48]. We re-classified the land cover types defined by IGBP into six types-water, shrublands and forest, grasslands, croplands, urban areas, and snow and ice - to analyze the effects of different land cover types on the accuracy of snow classification (Figure 1).

\subsection{SRTM Digital Elevation Model (DEM)}

The SRTM DEM (V004) data are from the National Map Seamless Data Distribution Systems (http://seamless.usgs.gov/) and were measured by NASA and the National Imagery and Mapping Agency (NIMA) of the US Department of Defense. The present DEM data for regions of China have a $90 \mathrm{~m}$ resolution. Previous studies showed that the data accuracy in the vertical direction is less than 16 $\mathrm{m}$ [49]. We re-sampled the original DEM data by using the nearest neighbor interpolation method and obtained a digital elevation model with a $500 \mathrm{~m}$ spatial resolution. 


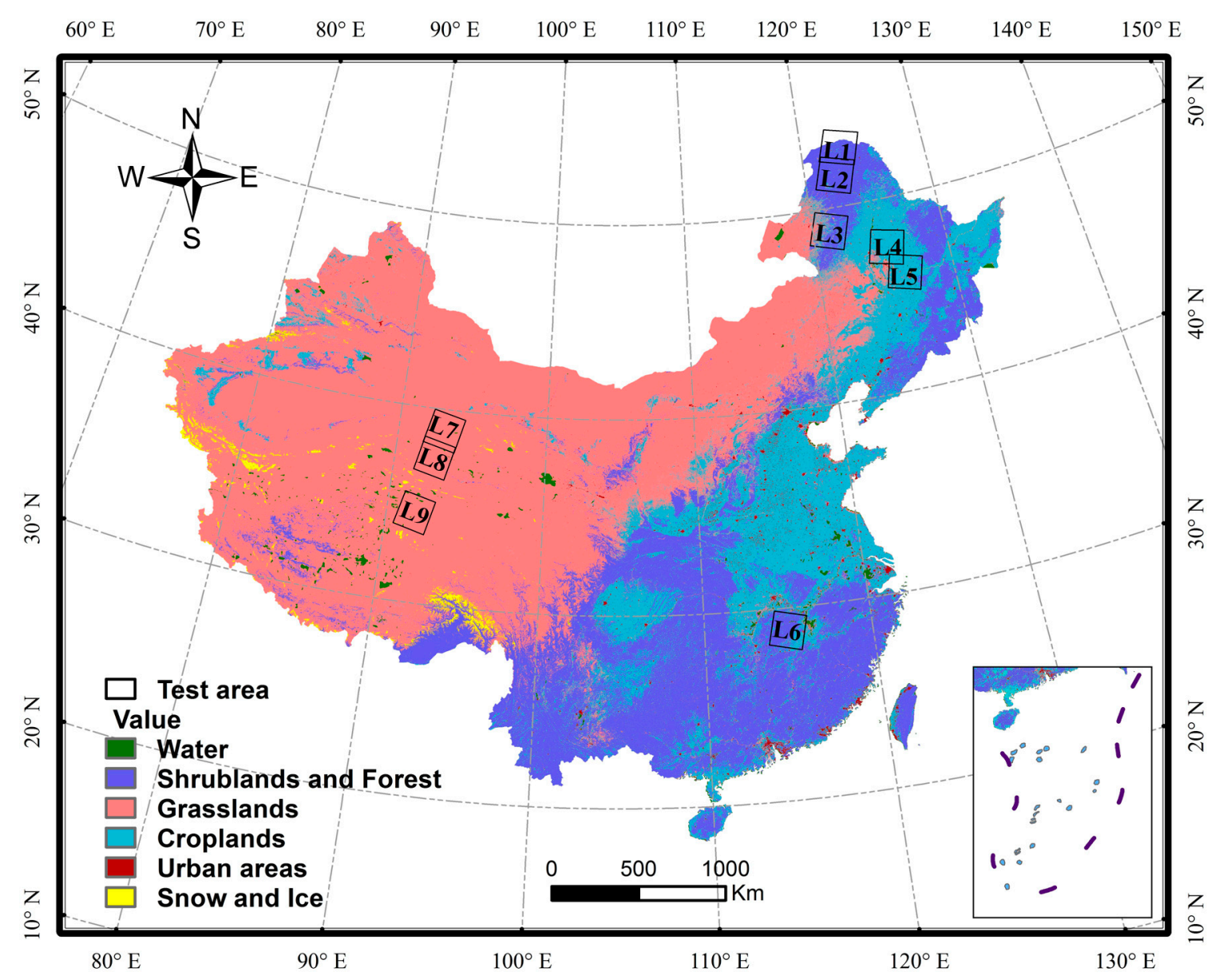

Figure 1. Spatial distribution of land cover types in China.

\section{Methodology}

\subsection{OLI Snow Mapping}

By adopting the SNOWMAP algorithm [50], we calibrated the radiometer, corrected atmosphere based on ENVI/flaash model and calculated NDSI using the third and sixth bands in OLI images. The set threshold value is 0.4 . The calculation equation is as follows:

$$
\mathrm{NDSI}=(\text { Band } 3-\text { Band } 6) /(\text { Band } 3+\text { Band } 6)
$$

Next, we set Band 5 to $>0.11$ to remove the water body interference, thereby producing a binary snow classification map with a $30 \mathrm{~m}$ resolution. The cloud pixels were interpreted and masked by artificial visual interpretation. Then, by using the Pixel Aggregate tool, we performed elevation calculations and obtained an FSC image with a $500 \mathrm{~m}$ resolution [44]. Take the OLI image of the test area L9 as an example (Figure 2), the produced binary and FSC snow maps show a very well agreement with the snow distribution in true color composite image. Which indicate that the OLI FSC snow map can be as the ground truth to validate the MODIS snow products due to its higher spatial resolution $[23,43,44]$. 


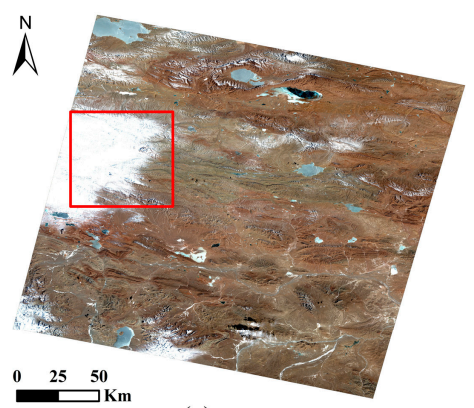

(a)

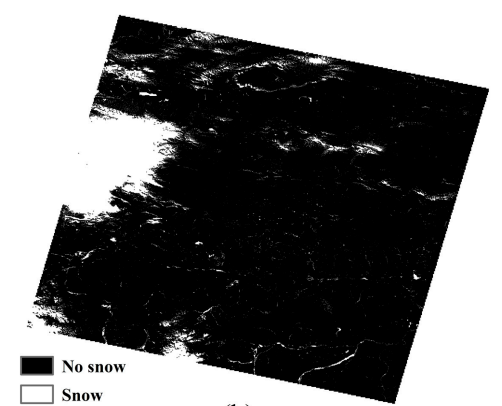

(b)

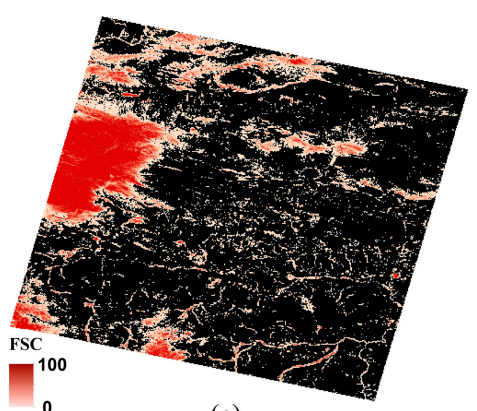

(c)

Figure 2. True color composite image (a), binary snow map (b) and fractional snow map (c) of OLI on 16 January 2014 in Tibetan Plateau.

\subsection{Cloud Removal Algorithm}

\subsubsection{Daily Composite}

Because clouds are mobile, the quantities of cloud in the daily snow products MOD10A1 and MYD10A1 differ. Thus, we combined the MODIS/Terra and MODIS/Aqua daily FSC products given by MOD10A1 and MYD10A1. The combination rule is shown in Table 3.

Table 3. Rules for compositing MOD10A1 and MYD10A1.

\begin{tabular}{ccccccc}
\hline MOD10A1 & \multicolumn{7}{c}{ MYD10A1 Code Values } \\
\cline { 2 - 6 } Code Values & $\mathbf{0 - 1 0 0}$ & $\mathbf{2 2 5}$ & $\mathbf{2 3 7}$ & $\mathbf{2 3 9}$ & $\mathbf{2 5 0}$ & $\mathbf{2 0 0} \backslash \mathbf{2 0 1} \backslash \mathbf{2 5 4} \backslash \mathbf{2 5 5} *$ \\
\hline $\mathbf{0 - 1 0 0}$ (Snow) & (MOD + MYD) $\times 0.5$ & MOD & MOD & MOD & MOD & MOD \\
$\mathbf{2 2 5}$ (Land) & MYD & 225 & 225 & 225 & 225 & 225 \\
$\mathbf{2 3 7}$ (Inland water) & MYD & 237 & 237 & 237 & 237 & 237 \\
$\mathbf{2 3 9}$ (Ocean) & MYD & 239 & 239 & 239 & 239 & 239 \\
$\mathbf{2 5 0}$ (Cloud) & MYD & 225 & 237 & 239 & 250 & 250 \\
$\mathbf{2 0 0} \backslash \mathbf{2 0 1} \backslash \mathbf{2 5 4} \backslash \mathbf{2 5 5} *$ & MYD & 225 & 237 & 239 & 250 & $200 \backslash 201 \backslash 254 \backslash 255$ \\
\hline
\end{tabular}

* The values 200, 201, 254 and 255 represent missing data, no decision, detector saturated and fill, respectively.

\subsubsection{Adjacent Temporal Composite}

Because snow cover can remain for relatively long durations on land, we merged the combined data above with the data before and after that day. If a pixel is cloudy and has snow cover on the days before and after, the mean FSC is calculated for the day before and the day after to replace the cloudy pixel on the specified day. If the pixel is bare land on the days before and after, the cloudy pixel is replaced with land; otherwise, the cloudy pixel remains the same.

\subsubsection{Snow Line Algorithm (SNOWL)}

The SNOWL process re-classifies labeled cloud pixels by using elevation data and the characteristics of the snow cover spatial distribution, which can only divide most part of the cloud pixels into snow and snow-free categories [38]. To reduce error, we first re-divided the regions in China into 34 sub-regions based on digital elevation model, then calculate the mean elevations of all the snow pixels and land pixels to get the information of snow line of different sub-regions, and then relabeled cloud pixels in 
different sub-regions based on the SNOWL algorithm. The distinguishing rules are as follows: (a) If a cloud pixel elevation is less than or equal to the mean land elevation in the corresponding region, this pixel is defined as land with a value of 0 . (b) If a cloud pixel elevation is greater than or equal to the mean snow elevation in the corresponding region, this pixel is defined as snow with a value of 300 . (c) If a cloud pixel elevation is between the mean land elevation and the mean snow elevation in the corresponding region, the value of the pixel remains the same.

\subsubsection{Composite with AMSR2 SWE}

To eliminate the strip gaps in the AMSR2 SWE product, we used the day before and after composite method to fill in missing data with maximum values and then used the nearest neighbor interpolation method to re-sample the composite gap-free product at a $500 \mathrm{~m}$ resolution, in agreement with the spatial resolution of the MODIS snow product. Then, we analyzed the re-sampled data from the SWE product in Section 3.2.3 using local grid calculations. If the SWE value is 0 , the corresponding cloud pixel is classified as land with a value of 0 ; if the SWE value is higher than 0 , the corresponding cloud pixel is classified as snow with a value of 300 .

\subsubsection{Iterative Operation}

On the basis of the gradual composite in the previous four steps, cloud pixels are almost completely removed. However, in Sections 3.2.3 and 3.2.4, whether the FSC is unknown of those pure snow pixels (value $=300$ ) which need to be converted to FSCs by iterative calculations. The iterative calculations replace the composite pure snow pixels on the specified day with the corresponding FSCs on the day before and after. If a pixel is marked as 300, the FSC is calculated for the day before and the day after to replace the pixel on the specified day, the mean FSC will instead of the pure snow pixel, and is repeated until the pure snow pixels are completely converted to FSCs. Finally, a daily cloud-free FSC product is formed with a $500 \mathrm{~m}$ resolution. The whole composite procedure is shown in Figure 3.

\subsection{Validation}

We use the high-resolution FSC map generated by the Landsat 8 OLI image as a true value to test the accuracy of the cloud-free FSC product developed in this study. We performed statistical calculations of the true value, the mean absolute error (MAE), root mean square error (RMSE), determination coefficient $\left(\mathrm{R}^{2}\right)$, and mean FSC between the two products, and we analyzed the accuracy of the composite FSC product. The equations to calculate MAE, RMSE and $\mathrm{R}^{2}$ are as follows:

$$
\begin{gathered}
M A E=\frac{1}{N} \sum_{1}^{N}\left|F_{\text {MODIS }}-F_{\text {OLI }}\right| \\
R M S E=\sqrt{\frac{1}{N} \sum_{1}^{N}\left(F_{\text {MODIS }}-F_{O L I}\right)^{2}} \\
R^{2}=\frac{\left[\sum_{1}^{N}\left(F_{M O D I S}-\overline{F_{M O D I S}}\right)\left(F_{O L I}-\overline{F_{O L I}}\right)\right]^{2}}{\sum_{1}^{N}\left(F_{\text {MODIS }}-\overline{F_{M O D I S}}\right)^{2} \bullet \sum_{1}^{N}\left(F_{O L I}-\overline{F_{O L I}}\right)^{2}}
\end{gathered}
$$


in which $F_{M O D I S}$ is the FSC value in the composite cloud-free FSC map and FOLI is the FSC value in the OLI image.

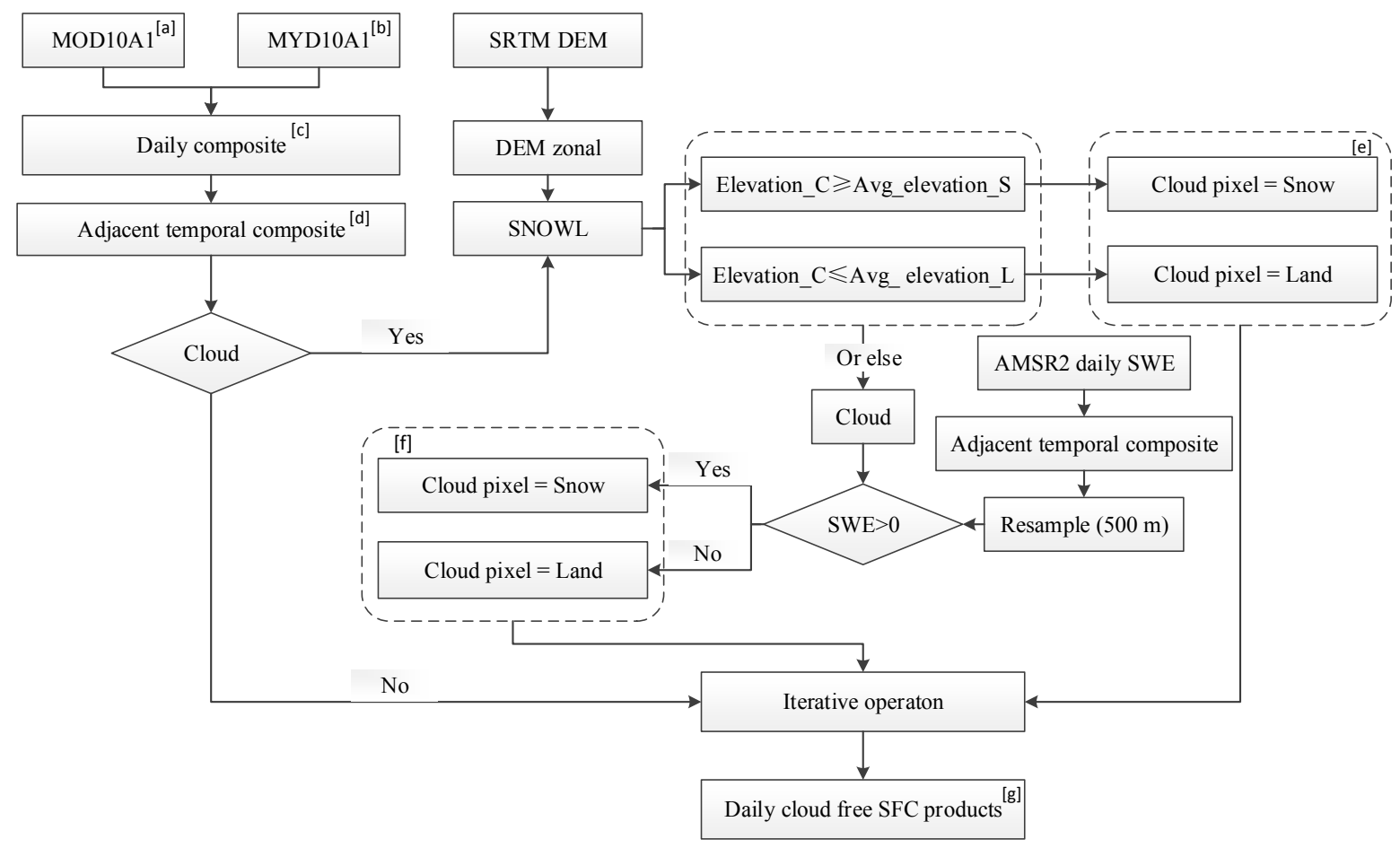

Figure 3. Flow chart for the daily cloud-free MODIS FSC product (The label from $\mathbf{a}-\mathbf{g}$ response to the same stages $\mathbf{a}-\mathbf{g}$ in Figure 4).

\section{Results}

\subsection{Effect of Cloud Removal}

An example on 16 January 2014 is shown in Figure 4. The MODIS FSC standard product, MOD10A1 and MYD10A1 are largely contaminated by cloud. For reference, the MOD10A1 cloud amount is $50.35 \%$, and the MYD10A1 cloud amount is $47.61 \%$. After merging the data from the morning and afternoon, the daily composite product cloud amount is $39.97 \%$. Following the SNOWL data process, the cloud amount decreases to $3.05 \%$, and $9.84 \%$ is re-classified as pure snow (300). Then, after combination with AMSR2 data, the clouds are completely removed and pure snow (300) reaches 11.38\% (Figure 5). Figure 4 shows that the cloud-removal algorithm in this study can effectively remove cloud contamination to obtain a daily cloud-free FSC product. Figure 5 shows the statistical results of the MODIS cloud amounts in the morning and afternoon, and the degree of cloudiness decreased in different composite steps during November 2013 to February 2014. During the composite process of the daily cloud-free FSC product, cloud contamination is gradually removed, and the snow-covered area in the map also gradually increases. 
(a)

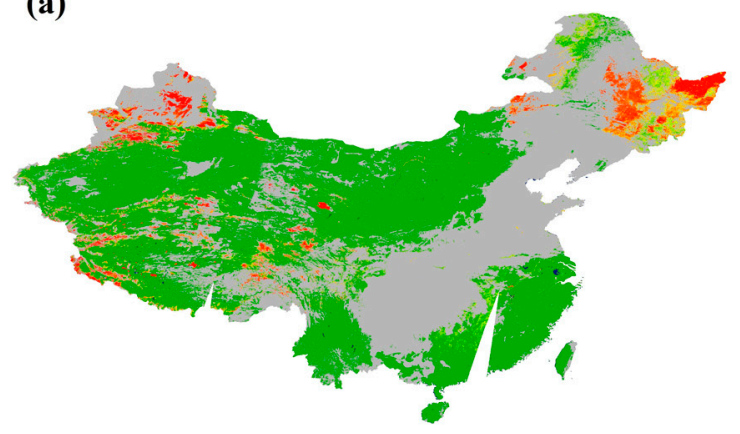

(c)

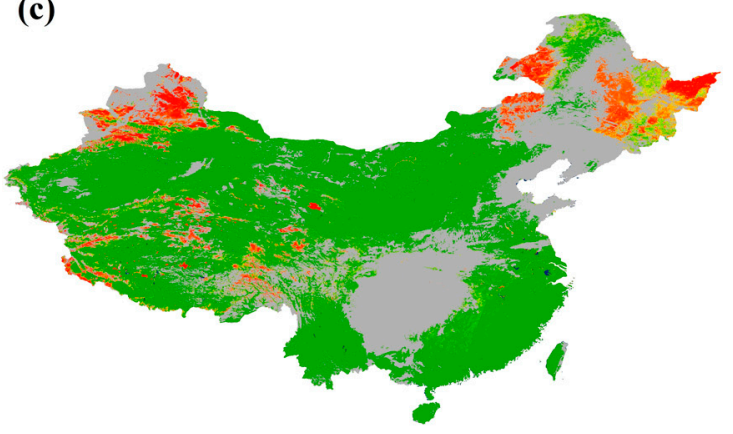

(e)

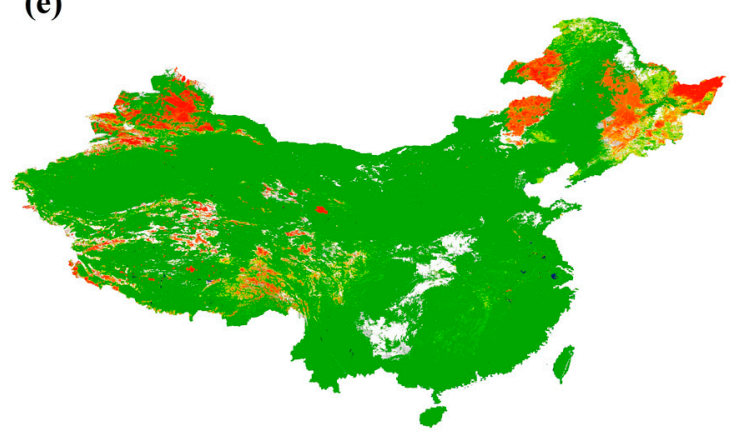

(g)

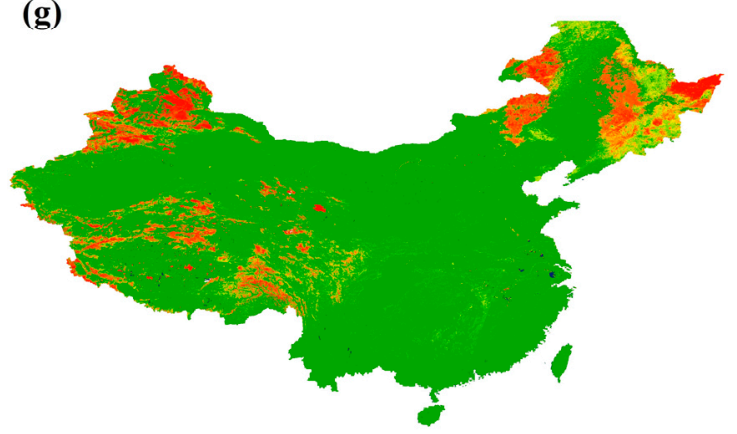

(b)

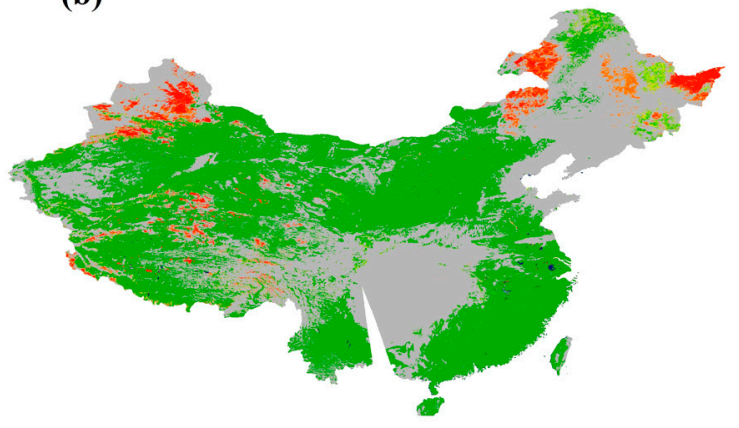

(d)

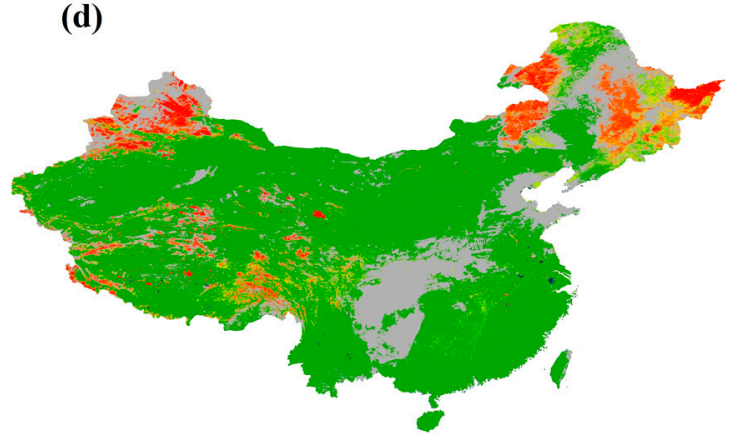

(f)
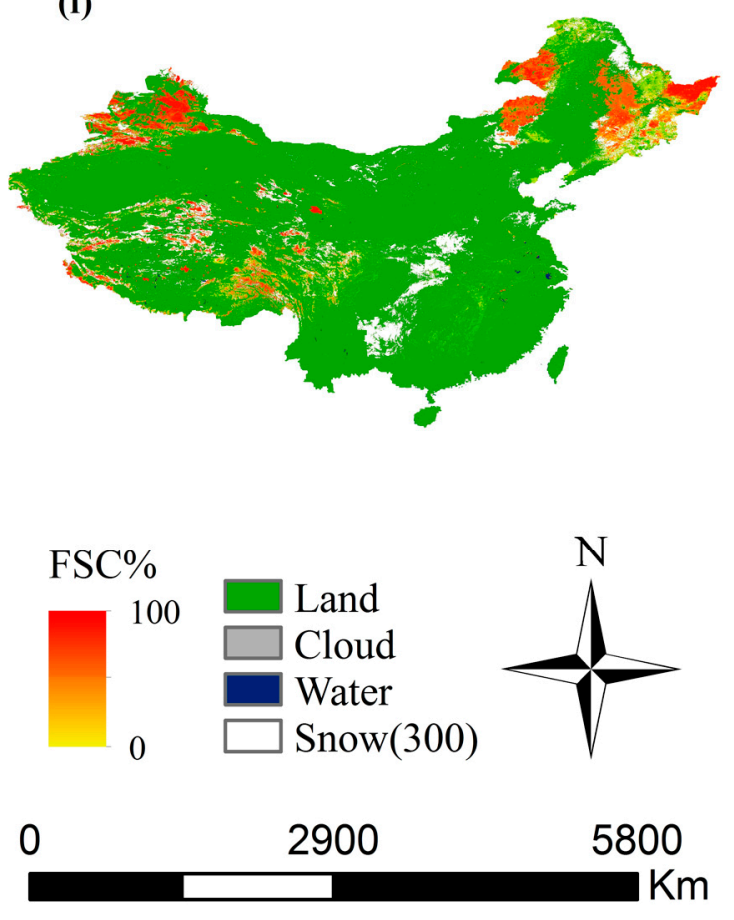

Figure 4. Cloud cover map on 16 January 2014. (a) MOD10A1; (b) MYD10A1; (c) composite morning and afternoon map; (d) day-before-and-after composite map; (e) SNOWL with cloud removed; (f) composite map with AMSR2; (g) daily cloud-free FSC product. 


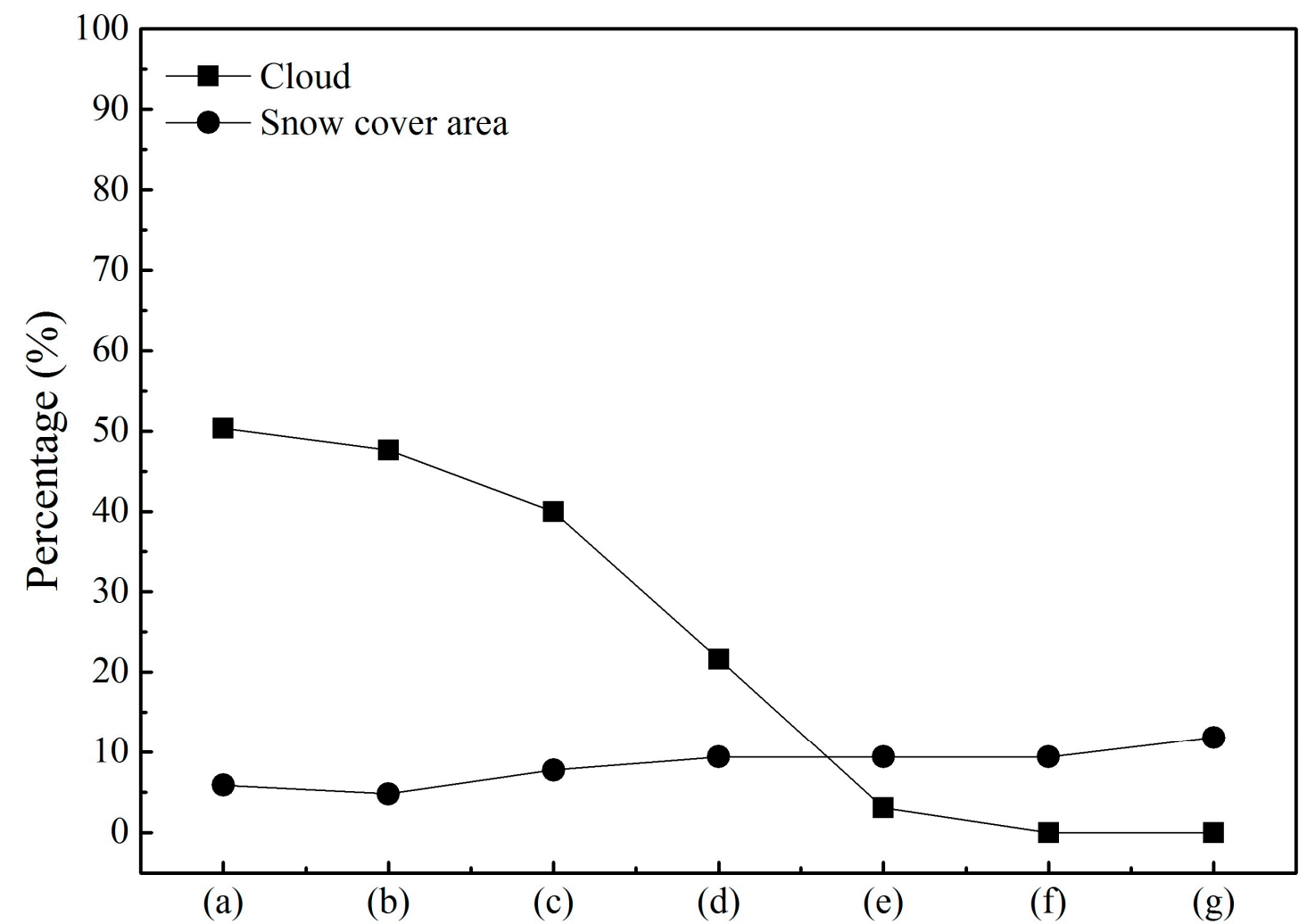

Figure 5. Plots of mean snow and cloud amount ratios during the different composite stages during November 2013 to February 2014. (a) MOD10A1; (b) MYD10A1; (c) morning and afternoon composite map; (d) day-before-and-after composite map; (e) SNOWL with cloud removed; (f) composite map with AMSR2; (g) daily cloud-free FSC product.

\subsection{Accuracy Test of the Daily Cloud-Free FSC Product}

Since clouds are always changing in both position and extent, one place (or a group of pixels) which is covered by cloud in the sometime is likely to be clear in the other time, and vice versa. We evaluated the accuracy of the composite daily cloud-free FSC map based on the FSC image obtained from the chosen cloud free Landsat 8 OLI. Only part of representative area as detail to show the effect of cloud removal algorithm, the results are shown in Figure 6 . The figure shows that the MOD10A1 and MYD10A1 images of the exhibition region are strongly affected by clouds on 16 January 2014. Especially in the MYD10A1 image, the snow-covered area is almost completely blocked by clouds. Based on the cloud-removal algorithm in this study, the resulting cloud-free FSC map agrees well with the snow map given by Landsat 8 OLI, which demonstrates that the daily cloud-free FSC mapping algorithm developed in this study is quite reliable. Figure 7 shows that both the MOD10A1 and MYD10A1 were influenced by cloud seriously. Clearly, the majority of the Chinese mainland was covered by $50 \%$ cloudiness during November 2013 to February 2014. After cloud removal, the produced daily cloud free FSC products improved the snow-covered area, obviously. 

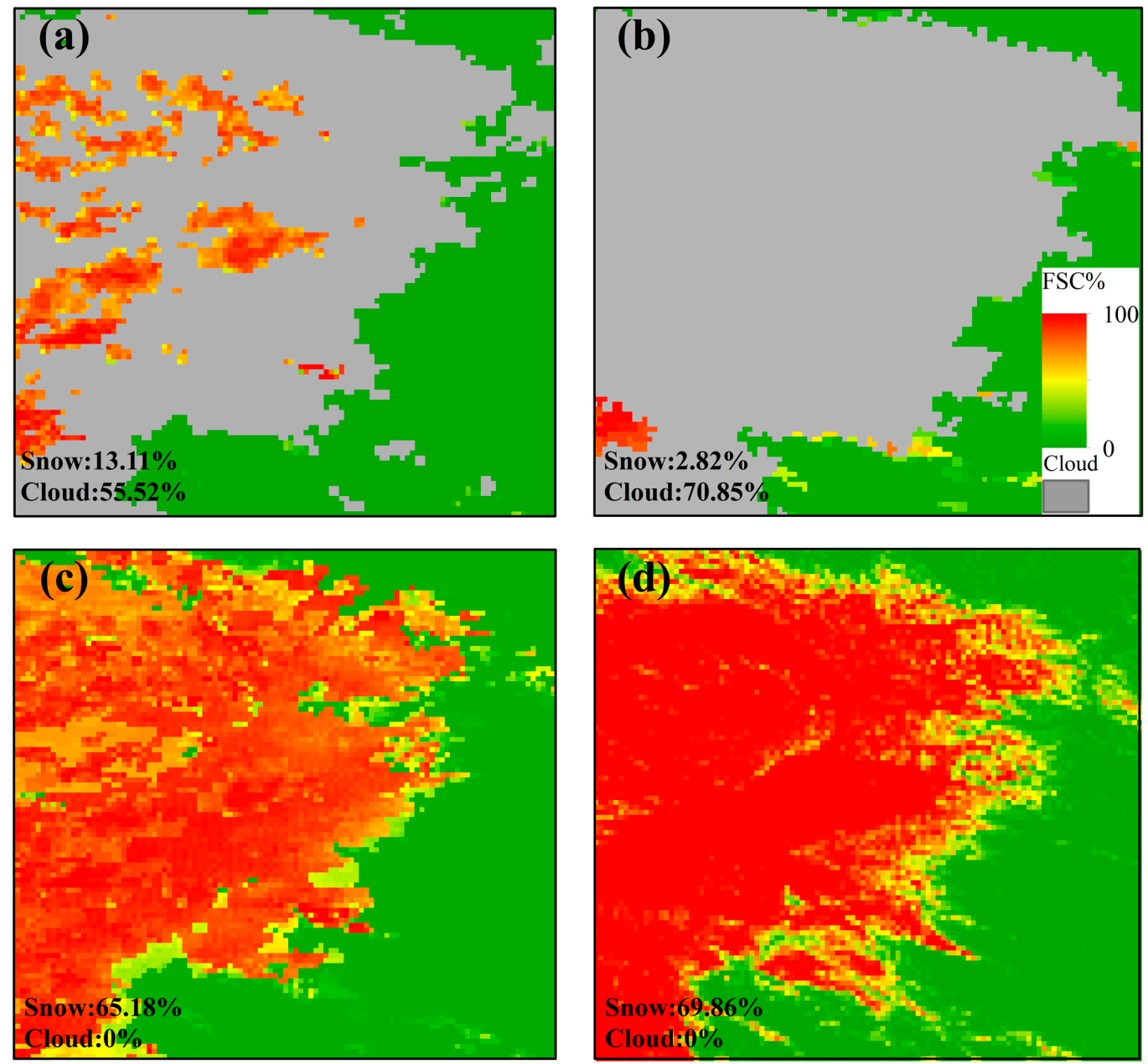

Figure 6. Fractional snow cover map for 16 January 2014. (a) MOD10A1; (b) MYD10A1; (c) final composite snow map; (d) OLI snow map.

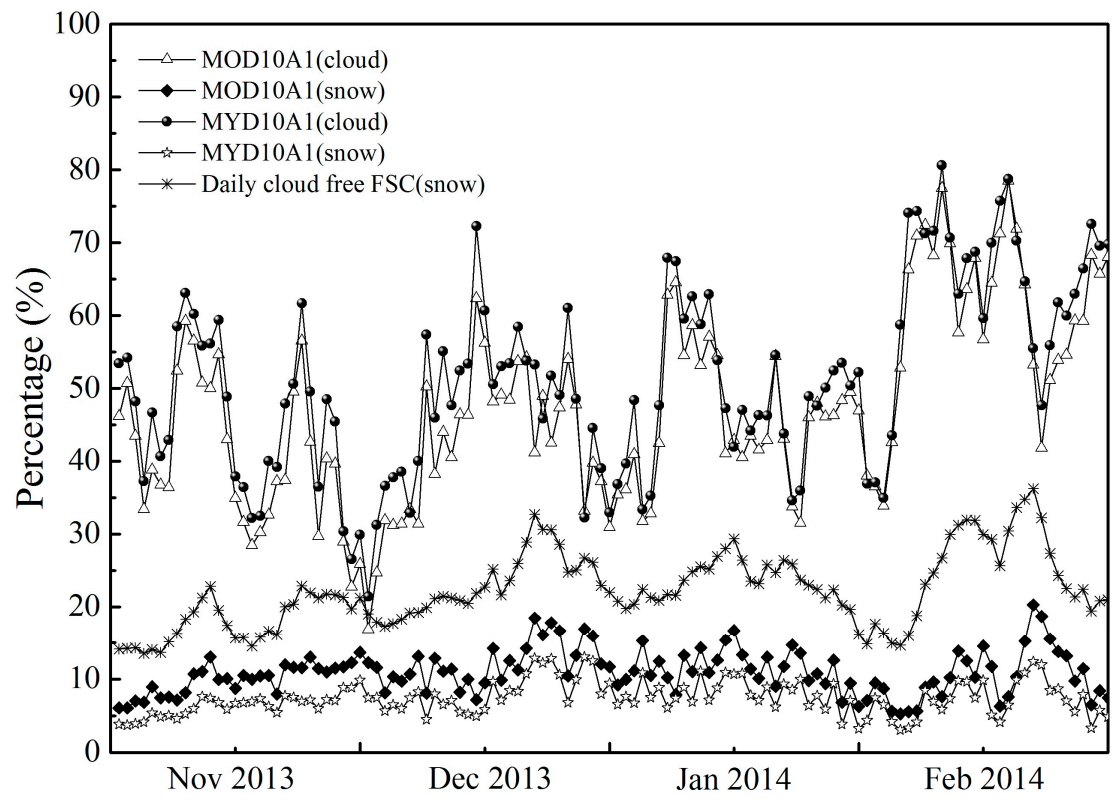

Figure 7. The curves of snow and cloud cover area retrieved from MOD10A1, MYD10A1 and produced daily cloud free FSC products during November 2013 to February 2014 in China. 
Further accuracy analysis results are shown in Table 4. Table 4 compares our daily cloud-free FSC product with the OLI FSC product under various land cover type conditions. The MAE and the RMSE between the two are the lowest under the grassland covered condition are 0.04 and 0.13 , respectively, with the highest determination coefficient of 0.91 . This is better than the results of Tang's algorithm conducted in Tibetan Plateau [45]. The accuracy under the shrublands and forest condition is not good, and the two are not well correlated. The snow identification accuracy is always worse in shrublands and forest area due to the influence of vegetation when using optical remote sensing $[9,23,33]$. The mean absolute error and the RMSE of the cropland area are the highest, but the two are well correlated, with the determination coefficient of 0.82 . The overall mean absolute error and the RMSE are 0.20 and 0.29, respectively. Also, the determination coefficient is 0.70 . Figure 8 compares the FSC values given by MOD10A1, MYD10A1, the daily cloud-free FSC product and the OLI FSC product in different test regions. The results show that the daily cloud-free FSC product improved the accuracy of snow-cover area monitoring compared with MOD10A1 and MYD10A1. In the grassland region, the obtained FSC values generally agree with OLI snow map (the two values only differ by $0.45 \%$ ), whereas in other regions, the two results are quite different (the cropland region features the maximum difference of $12.31 \%$ ).

Table 4. Error analysis of the produced daily cloud-free FSC products compared with OLI image.

\begin{tabular}{cccc}
\hline Land Cover Types & MAE & RMSE & $\mathbf{R}^{\mathbf{2}}$ \\
\hline Shrublands and Forest & 0.21 & 0.28 & 0.40 \\
Grasslands & 0.04 & 0.13 & 0.91 \\
Croplands & 0.32 & 0.46 & 0.82 \\
Urban areas & 0.22 & 0.32 & 0.65 \\
Overall & 0.20 & 0.29 & 0.70 \\
\hline
\end{tabular}

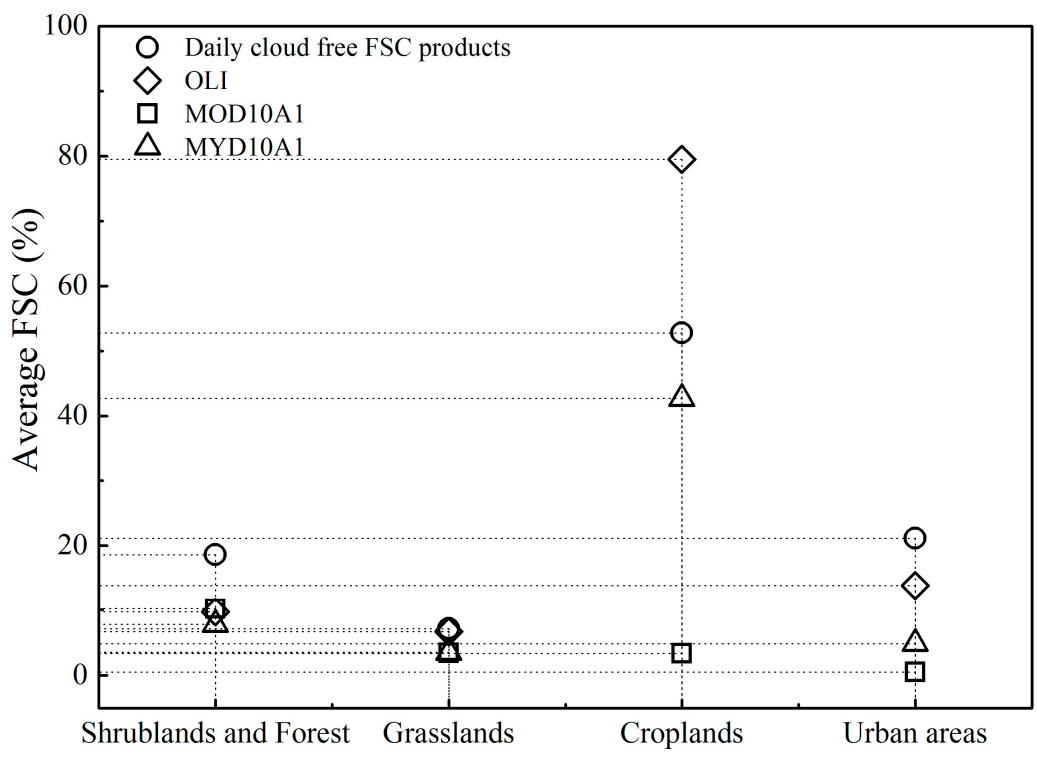

Figure 8. The mean FSCs of the MOD10A1, MYD10A1 and OLI image and the daily cloud-free FSC mapping for different land cover types in the text area during November 2013 to February 2014. 


\subsection{Error Analysis}

Figures 9-11 show the effects of elevation, aspect, slope, and land roughness on the accuracy of the produced daily cloud-free FSC product compared with Landsat 8 OLI snow map in shrublands and forest (L1, L2 and L3), the cropland (L4, L5 and L6) and alpine grassland test regions (L7, L8 and L9), respectively. The surface roughness was calculated by using the standard deviation of the elevation values in a $3 \times 3$ pixels window [51]. Figure 9 shows that with increasing slope, land roughness and elevation in the Northeast China forest region, the RMSE increases; in contrast, the effect of aspect is not significant. Figure 10 shows that in the South China cropland region, the RMSE increases with increasing slope and land roughness but decreases with increasing elevation. In contrast, the effects of aspect exhibit no pattern. Figure 11 shows that in the alpine grassland region on the Tibetan Plateau, the RMSE increases with increasing slope, land roughness and elevation, and the effect of aspect is not significant.
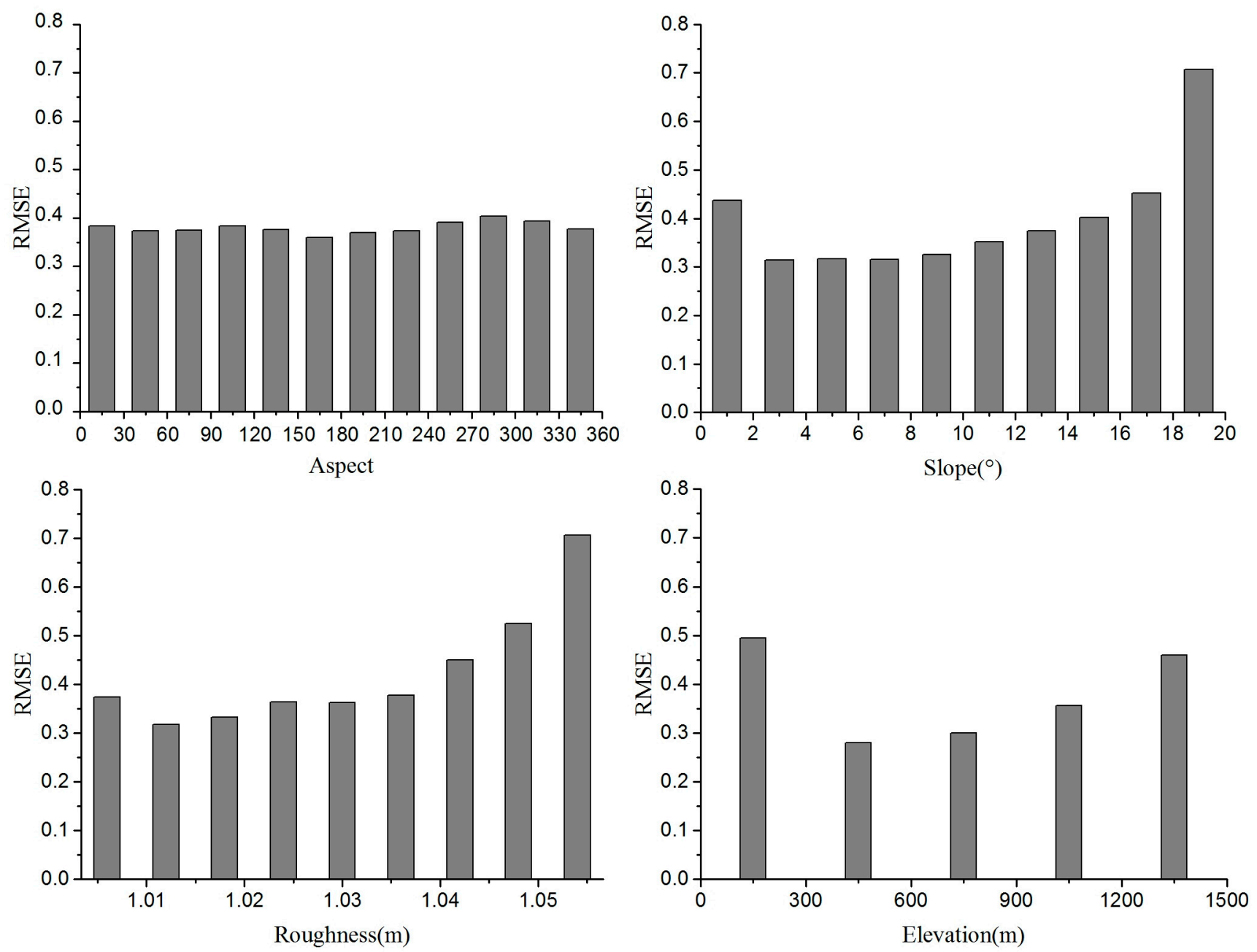

Figure 9. RMSE as a function of aspect, slope, roughness and elevation in shrublands and forest. 

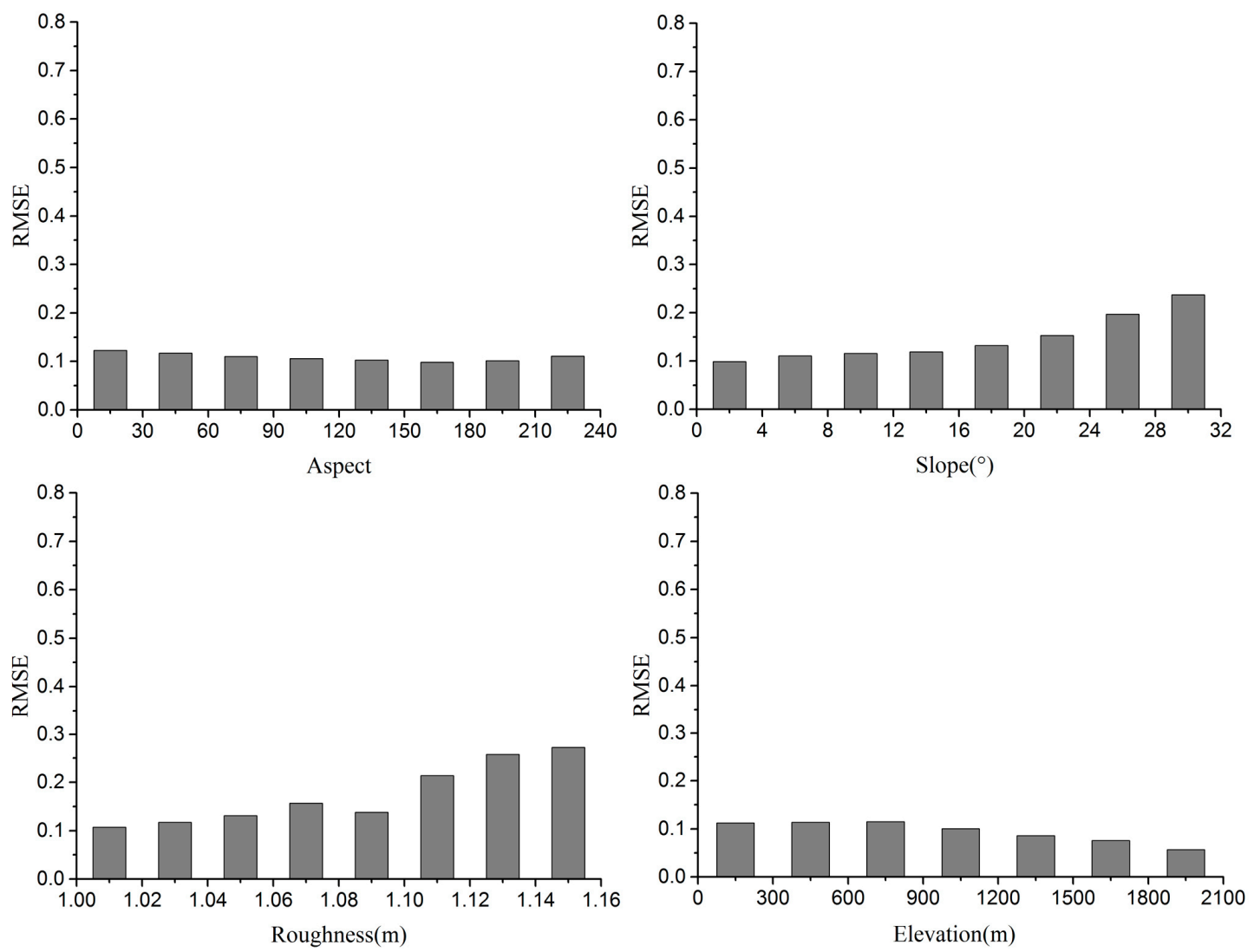

Figure 10. RMSE as a function of aspect, slope, roughness and elevation in croplands.
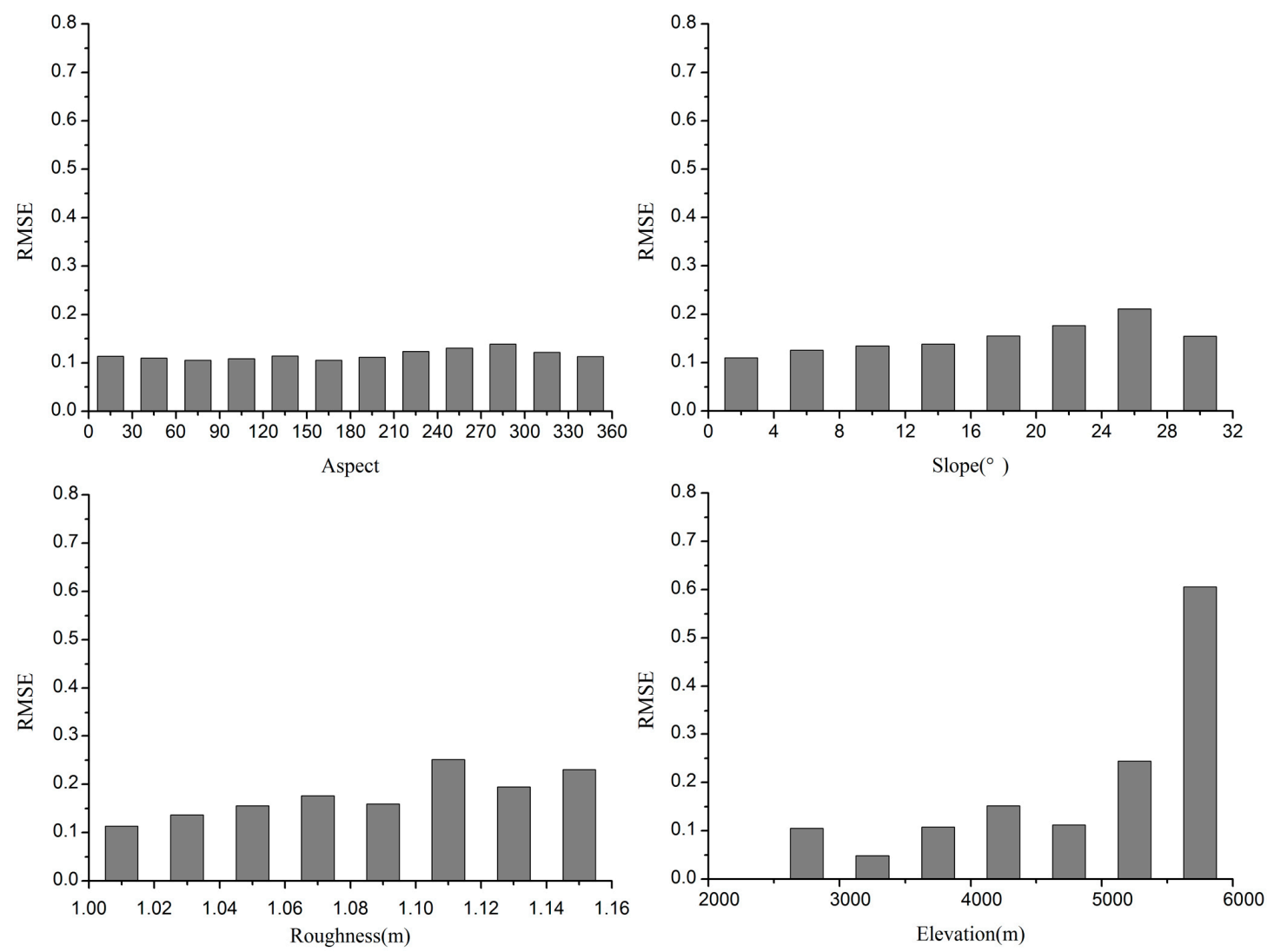

Figure 11. RMSE as a function of aspect, slope, roughness and elevation in alpine grasslands. 


\section{Discussions}

The general method for removing clouds in current optical remote sensing snow products is to combine multi-day data. Using this process, clouds can be more effectively removed by increasing the composite period while scarifying temporal resolution [31-33]. In addition, clouds can be completely removed by directly incorporating microwave snow water equivalent data. However, due to the low resolution of microwave data, this process results in a lower accuracy of the composite snow products. In situations with large quantities of clouds, errors are much higher [36,37]. Thus, we developed this set of cloud-removal algorithms primarily based on remote sensing data to combine the advantages of different cloud-removal algorithms, which include microwave snow water equivalent data when it is necessary to remove a large quantity of clouds. Our results show that the MODIS standard daily FSC product is strongly affected by clouds. During November 2013 to February 2014, the averaged morning and afternoon cloud amount in the MODIS snow product was approximately $50 \%$ for the studied regions in China, and this product therefore cannot effectively calculate snow-covered areas. By removing clouds using the cloud-removal method developed in this study, the cloud amount was sequentially decreased, and after the data were combined with the AMSR2 snow water equivalent data, cloud pixels were completely removed. Finally, a daily cloud-free FSC product for regions in China was obtained.

The FSC product obtained by the OLI sensor carried by the Landsat 8 satellite was used to test our daily cloud-free FSC product. The test results show that in addition to the complete removal of clouds, our product also effectively improves the accuracy of snow area monitoring. Compared to the OLI snow cover map, the mean error of our daily cloud-free FSC product is 0.19 , and the corresponding RMSE is 0.27 . However, different land use types affect the accuracy of our product. The accuracy is highest in the alpine grassland region and lowest in the forest region due to the effects of vegetation [18,49]. Due to the heat island effect, snow melts relatively fast in urban regions. Additionally, the temporal difference between MODIS and Landsat 8 results in large errors. The cropland test region studied here is mainly located in South China with low snow quantities and high temperatures. Therefore, snow melts quickly in this region, which leads to large errors.

In addition, terrain factors can also affect the accuracy of our daily cloud-free FSC product. We compared the results of the produced daily cloud-free FSC product for different slopes, aspects, land roughnesses and elevations by calculating the RMSE between the daily cloud-free FSC products and the OLI snow map. The results show that with increasing slope, roughness and elevation, the RMSE also increases; in contrast, the effect of aspect on the error is not significant. Hao et al. (2008) found that in alpine areas such as Tibetan Plateau, the accuracy of snow classification is worse with the gradual increase of altitude, mainly due to the serious snow fragmentation and terrain shadow. To improve the accuracy of MODIS snow identification in the alpine areas, the moderate resolution of optical remote sensing images must be first corrected for topography [52]. However, because landcover is used in different ways in different regions, the associated effects are also variable, indicating that the accuracy of snow information extraction is primarily affected by terrain factors. The different effects of land surface parameters in different regions on the composite product are mainly caused by different properties of snow in space and the terrain and climate conditions. There are three stable snow-covered regions in China: northern Xinjiang, northeastern Inner Mongolia and the Tibetan Plateau snow-covered area [4]. In contrast, snow occurs infrequently in South China and often in association with rain, which 
makes the snow melt quickly. Therefore, the capture of snowfall information and snow monitoring using remote sensing data are difficult in this region. Additionally, snow monitoring in the forest region is also a large problem. Although the snow monitoring accuracy can be improved by correcting the vegetation index, the overall result is still not satisfying [9].

\section{Conclusions}

MODIS data are widely used in ecological, atmospheric and hydrological sensing areas because of their high spatial and temporal resolution. Because optical sensors are strongly affected by clouds, an effective statistical analysis of FSC cannot be realized based on snow cover products from optical sensors. Combining these data with passive microwave data, which are unaffected by clouds, is an effective way to improve the snow-covered area monitoring accuracy of the MODIS data. Based on the MODIS standard daily FSC product released by NASA, we developed a daily cloud-free FSC mapping algorithm by combining passive microwave data, the AMSR2 snow water equivalent product and digital elevation data to construct a daily cloud-free FSC product for regions in China. We also tested the accuracy of our daily cloud-free FSC product based on the higher accuracy snow map obtained from a Landsat 8 OLI image.

To summarize, the accuracy of the daily cloud-free product obtained from this study is improved in monitoring snow-covered area than that of the standard MODIS snow product (MOD10A1 and MYD10A1) compared with OLI FSC snow map, 20.6\% and 10.2\%, respectively. Furthermore, our product completely removes the interference of clouds. The obtained snow area data can also be used as reliable input parameters for certain hydrological and climate models. The composite product from this study was developed based on existing products. The validation tests show that the snow area monitoring accuracy of the standard MODIS product is not ideal in the forest and warm regions and needs to be improved, which is also an effective way to improve the accuracy of our FSC product.

\section{Acknowledgments}

This study was supported by the China State Key Basic Research Project (2013CBA01802), and Chinese National Natural Science Foundation of China (41101337, 31372367, and 31228021), and the Program for Changjiang Scholars and Innovative Research Team in University (IRT13019).

\section{Author Contributions}

Jie Deng, Xiaodong Huang and Tiangang Liang designed research; Jie Deng, Qisheng Feng and Xiaofang Ma performed research and analyzed the data; Jie Deng and Xiaodong Huang wrote the paper. All authors read and approved the final manuscript.

\section{Conflicts of Interest}

The authors declare no conflict of interest. 


\section{References}

1. Robinson, D.A.; Frei, A. Seasonal variability of Northern Hemisphere snow extent using visible satellite data. Prof. Geogr. 2000, 52, 307-315.

2. Groisman, P.Y.; Karl, T.R.; Knight, R.W.; Stenchikov, G.L. Changes of snow cover, temperature, and radiative heat balance over the Northern Hemisphere. J. Clim. 1994, 7, 1633-1656.

3. Li, X.; Cheng, G.; Jin, H.; Kang, E.; Che, T.; Jin, R.;Wu, L.; Nan, Z.; Wang, J.; Shen, Y. Cryospheric change in China. Global Planet. Change 2008, 62, 210-218.

4. Xu, L.N.; Shi, J.C.; Zhang, H.G.; Wu, S.L. Fractional snow cover estimation in Tibetan Plateau using MODIS and ASTER. IEEE Int. Geosci. Remote Sens. Symp. 2005, 3, 1940-1942.

5. Wang, J.; Li, H.; Hao, X.; Huang, X.; Hou, J.; Che, T.; Dai, L.; Liang, T.; Huang, C.; Li, H.; et al. Remote sensing for snow hydrology in China: Challenges and perspectives. J. Appl. Remote Sens. 2014, doi:10.1117/1.JRS.8.084687.

6. Wang, C.H.; Wang, Z.L.; Cui, Y. Snow cover of China during the last 40 years: Spatial distribution and interannual variation. J. Glaciol. Geocryol. 2009, 31, 301-310.

7. Dai, L.Y.; Che, T.; Wang, J.; Zhang, P. Snow depth and snow water equivalent estimation from AMSR-E data based on a priori snow characteristics in Xinjiang, China. Remote Sens. Environ. 2012, 127, 14-29.

8. Dai, L.Y.; Che, T. Spatiotemporal variability in snow cover from 1987 to 2011 in northern China. J. Appl. Remote Sens. 2014, 8, 084693.

9. Bai, Y.C.; Feng, X.Z. Introduction to some research work on snow remote sensing. Remote Sens. Technol. Appl. 1997, 12, 60-66.

10. Danker, R.; De Jong, S.M. Monitoring snow-cover dynamics in Northern Fennoscandia with SPOT VEGETATION images. Int. J. Remote Sens. 2004, 25, 2933-2949.

11. Hartman, R.K.; Rost, A.A.; Anderson, D.M. Operational processing of multi-source snow data. In Proceedings of the 63rd Annual Western Snow Conference, Reno, NV, USA, April 1995.

12. Xiao, X.; Zhang, Q.; Boles, S.; Rawlins, M.; Moore III, B. Mapping snow cover in the pan-Arctic zone, using multi-year (1998-2001) images from optical VEGETATION sensor. Int. J. Remote Sens. 2004, 25, 5731-5744.

13. Hall, D.K.; Riggs, G.A.; Salomonson, V.V.; DiGirolamo, N.E.; Bayr, K.J. MODIS snow-cover products. Remote Sens. Environ. 2002, 83, 181-194.

14. Che, T.; Li, X. Spatial distribution and temporal variation of snow water resources in China during 1993-2002. J. Glaciol. Geocryol. 2005, 27, 64-67.

15. Che, T.; Li, X.; Jin, R.; Armstrong, R.L.; Zhang, T.J. Snow depth derived from passive microwave-remote sensing data in China. Ann. Glaciol. 2008, 49, 145-154.

16. Yu, H.; Feng, Q.S.; Zhang, X.T.; Zhang, X.T.; Huang, X.D.; Liang, T.G. An approach for monitoring snow depth based on AMSR-E data in the pastoral area of Northern Xinjiang. Acta Agrestia Sin. 2009, 18, 210-216.

17. Liu, J.F.; Chen, R.S. Studying the spatiotemporal variation of snow-covered days over china based on combined use of MODIS snow-covered days and in situ observations. Theo. Appl. Climatol. 2011, 106, 355-363. 
18. Hall, D.K.; Foster, J.L.; DiGirolamo, N.E.; Riggs, G.A. Snow cover, snowmelt timing and stream power in the Wind River Range, Wyoming. Geomorphology 2012, 137, 87-93.

19. Rodell, M.; Houser, P.R. Updating a land surface model with MODIS-derived snow cover. J. Hydrometeorol. 2004, 5, 1064-1075.

20. Platnick, S.; King, M.D.; Ackerman, S.A.; Menzel, W.P.; Baum, B.A.; Riédi, J.C.; Frey, R.A. The MODIS cloud products: Algorithms and examples from Terra. IEEE Trans. Geosci. Remote Sens. 2003, 41, 459-473.

21. Gafurov, A.; Bárdossy, A. Cloud removal methodology from MODIS snow cover product. Hydrol. Earth Syst. Sci. 2009, 13, 1361-1373.

22. Hall, D.K.; Riggs, G.A. Accuracy assessment of the MODIS snow products. Hydrol. Processes 2007, 21, 1534-1547.

23. Klein, A.G.; Barnett, A.C. Validation of daily MODIS snow cover maps of the Upper Rio Grande river basin for the 2000-2001 snow season. Remote Sens. Environ. 2003, 86, 162-176.

24. Maurer, E.P.; Rhoads, J.D.; Dubayah, R.O.; Dennis, P.L. Evaluation of the snow covered area data product from MODIS. Hydrol. Process. 2003, 17, 59-71.

25. Simic, A.; Fernandes, R.; Brown, R.; Romanov, P.; Park, W. Validation of vegetation, MODIS, and GOES+ SSM/I snow-cover products over Canada based on surface snow depth observations. Hydrol. Processes 2004, 18, 1089-1104.

26. Wang, X.; Xie, H.; Liang, T.G. Evaluation of MODIS snow cover and cloud mask and its application in northern Xinjiang, China. Remote Sens. Environ. 2008, 112, 1497-1513.

27. Huang, X.D.; Liang, T.G.; Zhang, X.T.; Guo, Z. Validation of MODIS snow cover products using Landsat and ground measurements during the 2001-2005 snow seasons over northern Xinjiang, China. Int. J. Remote Sens. 2011, 32, 133-152.

28. Cheng, Q.; Shen, H.; Zhang, L.; Yuan, Q.; Zeng, C. Cloud removal for remotely sensed images by similar pixel replacement guided with a spatio-temporal MRF model. ISPRS J. Photogramm. Remote Sens. 2014, 92, 54-68.

29. Li, X.H.; Shen, H.; Zhang, L.; Yuan, Q.; Yang, G. Recovering quantitative remote sensing products contaminated by thick clouds and shadows using multitemporal dictionary learning. IEEE Trans. Geosci. Remote Sens. 2014, 52, 7086-7098.

30. Zeng, C.; Shen, H.F.; Zhang, L.P. Recovering missing pixels for Landsat ETM+ SLC-off imagery using multi-temporal regression analysis and a regularization method. Remote Sens. Environ. 2013, $131,182-194$.

31. Wang, X.; Xie, H. New methods for studying the spatiotemporal variation of snow cover based on combination products of MODIS Terra and Aqua. J. Hydrol. 2009, 371, 192-200.

32. Xie, H.; Liang, T.; Wang, X. Development and assessment of combined Terra and Aqua snow cover products in Colorado Plateau, USA and northern Xinjiang, China. J. Appl. Remote Sens. 2009, doi:10.1117/1.3265996.

33. Liang, T.G.; Huang, X.D.; Wu, C.X.; Liu, X.Y.; Li, W.L.; Guo, Z.G.; Ren, J.Z. An application of MODIS data to snow cover monitoring in a pastoral area: A case study in Northern Xinjiang, China. Remote Sens. Environ. 2008, 112, 1514-1526.

34. Parajka, J.; Blöschl, G. Spatio-temporal combination of MODIS images-potential for snow cover mapping. Water Resour. Res. 2008, doi:10.1029/2004JD005047. 
35. Hall, D.K.; Riggs, G.A.; Foster, J.L.; Kumar, S.V. Development and evaluation of a cloud-gap-filled MODIS daily snow-cover product. Remote Sens. Environ. 2010, 114, 496-503.

36. Gao, Y.; Xie, H.; Lu, N.; Yao, T.; Liang, T. Toward advanced daily cloud-free snow cover and snow water equivalent products from Terra-Aqua MODIS and Aqua AMSR-E measurements. $J$. Hydrol. 2010, 385, 23-35.

37. Liang, T.; Zhang, X.; Xie, H.; Wu, C.; Feng, Q.; Huang, X.; Chen, Q. Toward improved daily snow cover mapping with advanced combination of MODIS and AMSR-E measurements. Remote Sens. Environ. 2008, 112, 3750-3761.

38. Parajka, J.; Pepe, M.; Rampini, A.; Rossi, S.; Blöschl, G. A regional snow-line method for estimating snow cover from MODIS during cloud cover. J. Hydrol. 2010, 381, 203-212.

39. Huang, X.D.; Hao, X.H.; Feng, Q.S.; Wang, W.; Liang, T. A new MODIS daily cloud free snow cover mapping algorithm on the Tibetan Plateau. Sci. Cold Arid Reg. 2014, 6, 0116-0123.

40. Wang, W.; Huang, X.D.; Deng, J.; Xie, H.; Liang, T. Spatio-temporal change of snow cover and its response to climate over the Tibetan Plateau based on an improved daily cloud-free snow cover product. Remote Sens. 2015, 7, 169-194.

41. Roesch, A.; Wild, M.; Gilgen, H.; Ohmura, A. A new snow cover fraction parameterization for the ECHAM4 GCM. Clim. Dyn. 2001, 17, 933-946.

42. Dobreva, I.D.; Klein, A.G. Fractional snow cover mapping through artificial neural network analysis of MODIS surface reflectance. Remote Sens. Environ. 2011, 115, 3355-3366.

43. Zhang, Y.; Huang, X.; Hao, X.; Wang, J.; Wang, W.; Liang, T. Fractional snow-cover mapping using an improved endmember extraction algorithm. J. Appl. Remote Sens. 2014, doi:10.1117/1.JRS.8.084691.

44. Salomonson, V.V.; Appel, I. Estimating fractional snow cover from MODIS using the normalized difference snow index. Remote Sens. Environ. 2004, 89, 351-360.

45. Tang, Z.; Wang, J.; Li, H.; Yan, L. Spatiotemporal changes of snow cover over the Tibetan Plateau based on cloud-removed modereate resolution imaging spectroradiometer fractional snow cover product from 2001 to 2011. J. Appl. Remote Sens. 2012, doi:10.1117/1.JRS.7.073582.

46. USGS EROS Data Center. MODIS Reprojection Tool User's Manual; Release 4.1; 2011. Available online: https://lpdaac.usgs.gov/sites/default/files/public/mrt41_usermanual_032811.pdf (accessed on 13 February 2015).

47. Friedl, M.A.; Damien, S.M.; Tan, B.; Schneider, A.; Ramankutty, N.; Sibley, A.; Huang, X. MODIS collection 5 global land cover: Algorithm refinements and characterization of new datasets. Remote Sens. Environ. 2010, 114, 168-182.

48. He, Y.; Bo, Y. A consistency analysis of MODIS MCD12Q1 and MERIS Globcover land cover datasets over China. In Proceedings of 19th International Conference on Geoinformatics, Shanghai, China, 24-26 June 2011.

49. Huang, X.; Xie, H.; Liang, T.; Yi, D. Estimating vertical error of SRTM and map-based DEMs using ICESat altimetry data in the eastern Tibetan Plateau. Int. J. Remote Sens. 2011, 32, 5177-5196.

50. Dozier, J. Spectral signature of alpine snow cover from the Landsat Thematic Mapper. Remote Sens. Environ. 1989, 28, 9-22.

51. Carabajal, C.C.; Harding, D.J. ICESat validation of SRTM C-band digital elevation models. Geophys. Res. Lett. 2005, doi:10.1029/2005GL023957. 
52. Hao, X.H.; Wang, J.; Li, H.Y. Evaluation of the NDSI threshold value in mapping snow cover of MODIS. J. Glaciol. Geocryol. 2008, 30, 132-138.

(C) 2015 by the authors; licensee MDPI, Basel, Switzerland. This article is an open access article distributed under the terms and conditions of the Creative Commons Attribution license (http://creativecommons.org/licenses/by/4.0/). 